\title{
Cancers of the respiratory tract in mustard gas workers
}

\author{
D F EASTON,' J PETO, ${ }^{1}$ R DOLL ${ }^{2}$ \\ From the Section of Epidemiology, Institute of Cancer Research, Sutton, Surrey SM2 5PX, and Imperial \\ Cancer Research Fund, ${ }^{2}$ Cancer Epidemiology and Clinical Trials Unit, Radcliffe Infirmary, Oxford OX2 $6 H E$, \\ UK
}

ABSTRACT In a study of a cohort of 2498 men and 1032 women employed in the manufacture of mustard gas in Cheshire during the second world war $3354(95 \%)$ individuals were successfully traced for mortality to the end of 1984. Large and highly significant excesses were observed as compared with national death rates for deaths from cancer of the larynx (11 deaths observed, 4.04 expected, $p=0.003$ ), pharynx (15 observed, 2.73 expected, $p<0.001)$, and all other buccal cavity and upper respiratory sites combined (lip, tongue, salivary gland, mouth, nose) (12 observed, 4.29 expected, $\mathrm{p}=0.002)$. For lung cancer, a highly significant but more moderate excess was observed (200 observed, 138.39 expected, $p<0.001$ ). Significant excesses were also observed for deaths from acute and chronic non-malignant respiratory disease (131 observed, 91.87 expected and 185 observed, 116.31 expected, respectively). The risks for cancers of the pharynx and lung were significantly related to duration of employment. None of these results is substantially altered when expected numbers are calculated from Cheshire urban areas rather than national rates, although the relative risks for lung cancer and non-malignant respiratory disease are substantially reduced if rates for Merseyside, the nearest large conurbation, are used. The results provide strong evidence that exposure to mustard gas can cause cancers of the upper respiratory tract and some evidence that it can cause lung cancer and non-malignant respiratory disease. Significant excess mortality was also observed for cancers of the oesophagus (20 observed, 10.72 expected) and stomach (70 observed, 49.57 expected) but these excesses showed no consistent relation with time since first exposure or duration of exposure, and it is not clear whether they were caused by mustard gas or were due to a combination of chance and confounding.

Mustard gas (bis-2-chloroethyl sulphide) was first manufactured for use in the first world war when many hundreds of thousands of soldiers were poisoned by it.' Subsequently, the compound was found to be mutagenic in bacteria and carcinogenic in laboratory animals $^{2}$ and exposure to it was thought to be a possible cause of cancer in man.

Two types of exposure have been investigated: acute exposure resulting from use of the gas in war and chronic exposure in the course of its manufacture. The results of the first have been equivocal. British soldiers who received a pension for mustard gas poisoning were found to have a raised mortality from lung cancer; but most of these men also had chronic bronchitis and a similar excess of lung cancer was

Accepted 18 January 1988 found in pensioners with bronchitis who had not been exposed to the gas. ${ }^{3}$ United States veterans with mustard gas injury had a clearly increased mortality from pneumonia but only a slight and statistically not significant increase in mortality from lung cancer. ${ }^{14}$

Two studies of the effects of occupational exposure to mustard gas have provided evidence of a cancer hazard. Wada et al reported 33 deaths from respiratory cancer in Japanese workers who manufactured mustard gas and other poisons on the island of Okunojima between 1929 and 1945 when only 0.9 would have been expected, but few details were given of the exposed cohort and it is difficult to judge the reliability of the comparison. ${ }^{5}$ In the other study Manning et al reported an excess of laryngeal cancer ( 7 cases compared with 0.75 expected) and an increased mortality from cancer of the lung and pneumonia in 511 men who worked in a mustard gas 652 
factory in Cheshire during the second world war. ${ }^{6}$ The cohort studied by Manning et al constituted, however, only a small proportion of the total number of employees at this factory during the period mustard gas was manufactured. We have, therefore, reexamined the factory's engagement and discharge registers and carried out a more extensive study.

\section{Population and methods}

\section{FACTORY}

The factory, commissioned in April 1938, produced toxic gases (none of which was in fact used) until November 1944. Twenty four thousand tonnes of mustard gas and about 1000 tonnes of Larmine, a lachrymatory mixture of $70 \%$ bromobenzyl cyanide and $30 \%$ benzyl cyanide, were manufactured. Various arsenic compounds were also stored at the site but not manufactured there.

Gas escaped on several occasions and several hundred individuals suffered acute effects caused by small amounts of mustard gas, principally in the actual process plants. No deaths occurred and the main problems were blistering on the arms and acute effects on the eyes and respiratory tract.

\section{STUDY POPULATION}

Subjects were identified from three sources. The personnel department at the works maintained two registers (the "engagement" and "discharge" registers) of all employees joining or leaving the works between 1 January 1940 and the closure of the works in 1961. The registers contained details of 5792 and 5138 individuals respectively; for each individual the register contained his or her name, address, works number, age, sex, the date of starting or leaving, and a rough description of the type of work on which he or she was engaged. Individuals appearing on both the engagement and discharge registers were identified on the basis of this information.

The study population was defined as all individuals known from the engagement register to have started employment before the end of 1944, together with individuals who appeared on the discharge register but not on the engagement register. The population thus defined included 2498 men and 2096 women.

The date of first engagement was in some cases taken from the employment records of a nearby works operated by the same company as some workers were recruited via this works to the factory without being recorded on the factory engagement register. The 396 workers for whom no record of recruitment at either works could be found were assumed to have been engaged in April 1938, when the factory opened. Production of mustard gas started soon afterwards, and for the purposes of assessing the effect of time since first exposure and duration of exposure, exposure was taken to start on 1 July 1938 or the date of engagement (if later) and to cease on 30 November 1944 or the date of discharge (whichever was the earlier).

Many of the 2096 women worked for relatively short periods, mainly in jobs with little exposure to mustard gas. The 1044 women with less than one year's service were therefore excluded. The $\mathbf{7 4 5}$ men with less than one year's service were, however, retained as many of them were employed in process areas. Follow up began on 1 January 1945 and individuals whose names appeared in the engagement register entered the study on this date. Those appearing only on the discharge register entered the study on their date of discharge, or on 1 January 1945 , whichever was the later.

\section{FOLLOW UP}

The cohort was traced through the National Health Service Central Register (NHSCR) (table 1). Five per cent of the cohort (176 individuals) remain untraced. This trace rate was achieved despite the cohort being constructed from records more than $\mathbf{4 0}$ years old, and without exact dates of birth, because the start of the works coincided with the setting up of the NHSCR in 1939 , so that individuals could be traced by their address in the original 1939 register. By the close of follow up at the end of 1984 the population had been followed up for a total of 92271 person-years, an average of 26. 1 years. Death certificates were coded by the Office of Population Censuses and Surveys according to the 9th revision of the International Classification of Diseases. Since 1971 the NHSCR has recorded all cancer registrations in England and Wales, and any such registrations in this cohort were also notified to us, with site and histology coded according to MOTNAC ${ }^{7}$ or ICD- $0^{8}$ as appropriate.

\section{STATISTICAL ANALYSIS}

The principal analyses are based on a comparison of the mortality of the workforce for different causes of death with that for the population of England and Wales. Expected numbers were estimated by multiplying person-years at risk by the corresponding national death rates for England and Wales. Person-years and expected numbers were calculated for each sex and five

Table 1 Study population as at I January 1985

\begin{tabular}{lrrr}
\hline & Men & Women & Total \\
\hline Alive and traced & 637 & 486 & 1123 \\
Dead & 1655 & 475 & 2130 \\
Emigrated or armed forces & 72 & 29 & 101 \\
Untraced & 134 & 42 & 176 \\
Total & 2498 & 1032 & 3530 \\
\hline
\end{tabular}


Table 2 Observed $(O)$ and expected $(E)$ deaths from specified cancers in men and women, and standardised mortality ratios (SMRs)

\begin{tabular}{|c|c|c|c|c|c|c|c|c|c|}
\hline \multirow[b]{2}{*}{$\begin{array}{l}\text { Cancer site } \\
\text { (9th rev ICD code) }\end{array}$} & \multicolumn{2}{|l|}{ Men } & \multicolumn{2}{|c|}{ Women } & \multicolumn{2}{|c|}{ Total } & \multicolumn{3}{|c|}{$S M R$ based on: } \\
\hline & $O$ & $\boldsymbol{E}$ & $O$ & $\boldsymbol{E}$ & $O$ & $\boldsymbol{E}$ & $\begin{array}{l}\text { National } \\
\text { rates }\end{array}$ & $\begin{array}{l}\text { Merseyside } \\
\text { rates }\end{array}$ & $\begin{array}{l}\text { Cheshire } \\
\text { urbon rates }\end{array}$ \\
\hline $\begin{array}{l}\text { Lip (140) } \\
\text { Tongue (141) } \\
\text { Salivary gland (142) } \\
\text { Gum and mouth (143-145) } \\
\text { Pharynx (146-149) } \\
\text { Oesophagus (150) } \\
\text { Stomach (151) } \\
\text { Small intestine (152) } \\
\text { Colon (153) } \\
\text { Rectum (154) } \\
\text { Liver and gall bladder (155-156) } \\
\text { Pancreas (157) } \\
\text { Nose (160) } \\
\text { Larynx (161, 162.0) } \\
\text { Lung (162.1-162.9, 163) } \\
\text { Bone (170) } \\
\text { Connective tissue (171) } \\
\text { Skin (172, 173) } \\
\text { Breast (174, 175) } \\
\text { Uterus (182) } \\
\text { Ovary (183) } \\
\text { Prostate (185) } \\
\text { Testis (186) } \\
\text { Bladder (188) } \\
\text { Kidney (189) } \\
\text { Brain and CNS (191, 192) } \\
\text { Thyroid (193) } \\
\text { Non-Hodgkin's lymphoma (200, } \\
\text { 202) } \\
\text { Hodgkin's disease (201) } \\
\text { Multiple myeloma (203) } \\
\text { Leukaemia (204-208) } \\
\text { Benign \& unclassified (210-239) } \\
\text { All other neoplasms }\end{array}$ & $\begin{array}{r}1 \\
3 \\
2 \\
4 \\
13 \\
16 \\
53 \\
2 \\
21 \\
17 \\
5 \\
11 \\
2 \\
10 \\
189 \\
1 \\
0 \\
0 \\
1 \\
- \\
\\
8 \\
0 \\
8 \\
1 \\
5 \\
1 \\
9\end{array}$ & $\begin{array}{r}0.26 \\
1.32 \\
0.39 \\
0.99 \\
2 \cdot 14 \\
8.65 \\
41 \cdot 44 \\
0.62 \\
21 \cdot 06 \\
16.55 \\
5 \cdot 71 \\
13 \cdot 08 \\
0.67 \\
3.65 \\
127.68 \\
1.37 \\
0.65 \\
2 \cdot 16 \\
0.42 \\
-\quad \\
\\
17.69 \\
0.62 \\
13 \cdot 19 \\
4.91 \\
6.83 \\
0.57 \\
4.06 \\
2.02 \\
2.70 \\
6.46 \\
3.61 \\
10.93\end{array}$ & $\begin{array}{r}0 \\
0 \\
0 \\
0 \\
2 \\
4 \\
17 \\
1 \\
6 \\
1 \\
3 \\
5 \\
0 \\
1 \\
11 \\
0 \\
0 \\
0 \\
23 \\
10 \\
9 \\
- \\
\\
6 \\
0 \\
3 \\
0 \\
0\end{array}$ & $\begin{array}{c}0.01 \\
0.22 \\
0.09 \\
0.16 \\
0.59 \\
2.07 \\
8.13 \\
0.20 \\
9.06 \\
4.24 \\
1.99 \\
3.77 \\
0.18 \\
0.39 \\
10.71 \\
0.35 \\
0.24 \\
0.83 \\
20.17 \\
7.80 \\
7.00 \\
- \\
1.66 \\
1.06 \\
2.22 \\
0.47 \\
1.32 \\
0.52 \\
0.99 \\
2.05 \\
1.58 \\
4.57\end{array}$ & $\begin{array}{r}1 \\
3 \\
2 \\
4 \\
15 \\
20 \\
70 \\
3 \\
27 \\
18 \\
8 \\
16 \\
2 \\
11 \\
200 \\
1 \\
0 \\
0 \\
24 \\
10 \\
9 \\
8 \\
0 \\
14 \\
1 \\
8 \\
1 \\
9 \\
\end{array}$ & $\begin{array}{r}0.27 \\
1.54 \\
0.48 \\
1 \cdot 15 \\
2.73 \\
10.72 \\
49.57 \\
0.81 \\
30 \cdot 12 \\
20.79 \\
7.70 \\
16 \cdot 86 \\
0.85 \\
4.04 \\
138.39 \\
1.72 \\
0.89 \\
2.99 \\
20.59 \\
7.80 \\
7.00 \\
17.69 \\
0.62 \\
14.85 \\
5.97 \\
9.05 \\
1.03 \\
5.38 \\
\\
2.55 \\
3.69 \\
8.51 \\
5.19 \\
15.50\end{array}$ & 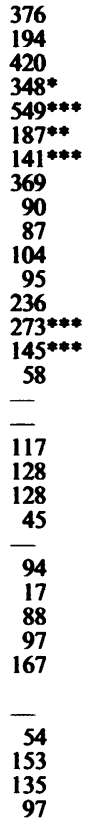 & $\begin{array}{c}- \\
- \\
- \\
\overline{140} \\
110 \\
\overline{70} \\
74 \\
78 \\
\overline{224} \\
103 \\
- \\
\overline{113} \\
\overline{155} \\
53 \\
\frac{69}{18} \\
87 \\
-\end{array}$ & $\begin{array}{l}- \\
- \\
- \\
\overline{189 * *} \\
139^{* * *} \\
\overline{72} \\
75 \\
\overline{87} \\
\overline{311 * * *} \\
162^{* * *} \\
- \\
- \\
118 \\
124 \\
41 \\
97 \\
15 \\
97 \\
- \\
-\end{array}$ \\
\hline All neoplasms (140-239) & 409 & $322 \cdot 40$ & 113 & $94 \cdot 64$ & 522 & $417 \cdot 04$ & $125 * * *$ & 98 & $126 * * *$ \\
\hline
\end{tabular}

"p $<0.05 ; * * p<0.01 ; * * * p<0.001$.

year age group up to age 85 , and for the calendar periods $1945,1946-50,1951-5, \ldots$ 1976-80, 1981-4. Follow up began on 1 January 1945 and ended on the date of emigration, death, the individual's 85th birthday, or 1 January 1985 , whichever was the sooner. Follow up was censored at age 85 for two reasons: firstly, death certification in old age is known to be unreliable and, secondly, death rates beyond age 85 are so high that the expected number of deaths may be substantially inflated by a few individuals incorrectly recorded as still alive beyond this age.

Of the 2130 recorded deaths, 147 occurred before 1945 or after age 85, leaving a total of 1983 deaths in the analysis.

Age specific death rates for the population of England and Wales were obtained from published tables ${ }^{9}$ or from data supplied by the Office of Population Censuses and Surveys. Since death rates vary between different parts of the United Kingdom, an attempt was made to find death rates appropriate to the locality of the plant. None is entirely satisfactory, but the rates for Cheshire urban areas 1969-73, published by the OPCS, ${ }^{10}$ would seem to be the most suitable, since this is about half way through the period when most of the deaths occurred. Adjusted SMRs in tables 2 and 3 have been calculated by multiplying expected deaths in each sex based on national rates by the SMRs for Cheshire urban areas for ages 15-64 for men and women. Adjusted SMRs using the corresponding rates for Merseyside have also been calculated, as a substantial proportion of the workforce have probably come from the Merseyside area. (Expected numbers given in the text refer to those calculated from national rates unless otherwise specified.) For cancers of the lip, tongue, salivary gland, mouth, and pharynx reliable local rates are not available and adjusted SMRs are calculated only for buccal cavity and pharynx as a whole.

The statistical significance of the excess of observed over expected has been assessed using the Poisson 
approximation." The effect of factors such as duration of employment on cause specific mortality have been assessed using standard tests for trend in relative risk. ${ }^{12}$ All significance levels quoted are one sided unless otherwise stated.

\section{Results}

\section{CANCER MORTALITY}

Table 2 shows observed and expected numbers of deaths from cancers of different sites. The two sites for which there is strong prior evidence of a risk of mustard gas, larynx and lung, show highly significant excesses by comparison with the numbers expected from national rates. In addition, there is an even larger relative excess of cancers of the pharynx (SMR $=549$, p < 0.001). An increased risk was observed for each pharyngeal site (observed/expected $=2 / 0.71$ for oropharynx, 4/0.51 for nasopharynx, 4/1.01 for hypopharynx, and $5 / 0.51$ for "other" pharynx) but this subdivision may not be reliable, especially in earlier years, and the pharynx is therefore considered as a single site in all analyses. Cancers of the lip, tongue, salivary gland, mouth, and nose are also all in excess, and the combined excess of these cancers of the buccal cavity and upper respiratory tract is also statistically significant (observed/expected 12/4-29, $S M R=280$, $\mathrm{p}=0.002$ ).

There are also relatively smaller but still highly significant increases in SMR for cancers of the oesophagus and stomach. For none of the remaining sites is there a significantly raised risk individually or overall, the total number of deaths observed from these other cancers (194) being close to that expected (207-3). Mustard gas has not been suggested as a risk factor for any of these other cancers and they will not be considered further.

Adjustment for Cheshire urban rates slightly increases the SMRs for cancers of the larynx and lung and leaves the SMRs for cancers of the oesophagus and stomach virtually unchanged. Each of the SMRs is, however, substantially reduced if Merseyside rates are used, and only the larynx remains significantly raised (see discussion). In the absence of reliable local death rates no adjustment could be made for cancers of the pharynx or of other sites in the head and neck. The SMR for buccal cavity and pharynx as a whole, however, is reduced from $\mathbf{4 0 5}$ using national rates to 316 using Merseyside rates, but remains highly significant $(p=0.002)$.

\section{NON-CANCER MORTALITY}

Table 3 shows observed and expected numbers of deaths from causes of death other than cancer. There are substantial and highly significant excesses for both influenza and pneumonia (SMR 143) and for chronic respiratory disease (SMR 159) by comparison with the numbers expected from national rates and both are further increased by adjusting for Cheshire urban districts. If Merseyside rates are used, however, both SMRs are substantially reduced (SMR 114, p = 0.08 and SMR 108, $p=0.16$ respectively). The slight excess of circulatory disease (SMR 108) disappears when local rates are used. For no other cause is there

Table 3 Observed $(O)$ and expected $(E)$ deaths from selected causes other than cancer in men and women and SMRs

\begin{tabular}{|c|c|c|c|c|c|c|c|c|c|}
\hline \multirow[b]{2}{*}{$\begin{array}{l}\text { Cause of death } \\
\text { (9th rev ICD code) }\end{array}$} & \multicolumn{2}{|l|}{ Men } & \multicolumn{2}{|c|}{ Women } & \multicolumn{2}{|l|}{ Total } & \multicolumn{3}{|c|}{ SMR based on: } \\
\hline & 0 & $\boldsymbol{E}$ & $\boldsymbol{O}$ & $\boldsymbol{E}$ & $\boldsymbol{O}$ & $\boldsymbol{E}$ & $\begin{array}{l}\text { National } \\
\text { rates }\end{array}$ & $\begin{array}{l}\text { Merseyside } \\
\text { rates }\end{array}$ & $\begin{array}{l}\text { Cheshire } \\
\text { urban rates }\end{array}$ \\
\hline $\begin{array}{l}\text { Infectious diseases (1-7, 10-139) } \\
\text { Endocrine nutritional, metabolic, } \\
\text { and blood diseases }(240-289)\end{array}$ & $\begin{array}{l}35 \\
15\end{array}$ & $\begin{array}{l}27 \cdot 61 \\
13 \cdot 23\end{array}$ & $\begin{array}{l}8 \\
8\end{array}$ & $\begin{array}{l}6 \cdot 21 \\
7 \cdot 41\end{array}$ & $\begin{array}{l}43 \\
23\end{array}$ & $\begin{array}{l}33 \cdot 83 \\
20 \cdot 63\end{array}$ & $\begin{array}{l}127 \\
111\end{array}$ & $\begin{array}{l}102 \\
119\end{array}$ & $\begin{array}{l}181^{* * *} \\
114\end{array}$ \\
\hline $\begin{array}{l}\text { Diabetes (250) } \\
\text { Mental disorders }(290-319) \\
\text { Nervous \& sense organs }(320-389) \\
\text { Circulatory diseases }(390-459) \\
\text { Ischaemic heart disease }(414) \\
\text { Cerebrovascular disease }(430-438) \\
\text { Respiratory disease }(460-519) \\
\text { Infiuenza \& pneumonia }(480-487) \\
\text { Bronchitis (460-466, } 490-492,494- \\
\text { 496) }\end{array}$ & $\begin{array}{r}10 \\
4 \\
15 \\
671 \\
358 \\
116 \\
283 \\
104 \\
165\end{array}$ & $\begin{array}{r}7.92 \\
2.69 \\
13.27 \\
646 \cdot 77 \\
382.72 \\
131.08 \\
198 \cdot 27 \\
71 \cdot 31 \\
105.94\end{array}$ & $\begin{array}{r}4 \\
3 \\
4 \\
206 \\
88 \\
53 \\
51 \\
27 \\
20\end{array}$ & $\begin{array}{r}4 \cdot 03 \\
1.38 \\
5.07 \\
166.41 \\
74 \cdot 01 \\
49 \cdot 10 \\
35 \cdot 25 \\
20.56 \\
10.36\end{array}$ & $\begin{array}{r}14 \\
7 \\
19 \\
877 \\
446 \\
169 \\
334 \\
131 \\
185\end{array}$ & $\begin{array}{r}11.95 \\
4.08 \\
18.34 \\
813 \cdot 18 \\
456 \cdot 73 \\
180 \cdot 18 \\
233.54 \\
91.87 \\
116.31\end{array}$ & $\begin{array}{l}117 \\
172 \\
104 \\
108^{*} \\
98 \\
94 \\
143^{* * *} \\
143^{* * *} \\
159^{* * *}\end{array}$ & $\begin{array}{c}146 \\
251 * \\
96 \\
91 \\
84 \\
83 \\
107 \\
114 \\
108\end{array}$ & $\begin{array}{l}132 \\
252^{*} \\
123 \\
103 \\
91 \\
88 \\
153^{* * *} \\
199^{* * *} \\
172^{* * *}\end{array}$ \\
\hline $\begin{array}{l}\text { Asthma (493) } \\
\text { Digestive disorders (520-579) } \\
\text { Peptic ulcer (531-533) } \\
\text { Cirrhosis (571) } \\
\text { Genitourinary disorders (580-629) } \\
\text { Nephritis and nephrosis (580-589) } \\
\text { II defined causes, etc } \\
\text { Accidents and violence (800-999) }\end{array}$ & $\begin{array}{r}7 \\
41 \\
16 \\
3 \\
19 \\
9 \\
6 \\
44\end{array}$ & $\begin{array}{r}4 \cdot 20 \\
37 \cdot 99 \\
16 \cdot 17 \\
4 \cdot 02 \\
24 \cdot 81 \\
11 \cdot 04 \\
8 \cdot 50 \\
42 \cdot 03\end{array}$ & $\begin{array}{r}2 \\
14 \\
3 \\
1 \\
12 \\
8 \\
7 \\
15\end{array}$ & $\begin{array}{r}1 \cdot 77 \\
10-89 \\
2 \cdot 26 \\
1 \cdot 44 \\
6 \cdot 19 \\
3 \cdot 25 \\
5 \cdot 30 \\
11 \cdot 30\end{array}$ & $\begin{array}{r}9 \\
55 \\
19 \\
4 \\
31 \\
17 \\
13 \\
59\end{array}$ & $\begin{array}{r}5 \cdot 97 \\
48 \cdot 89 \\
18 \cdot 44 \\
5 \cdot 46 \\
31 \cdot 00 \\
14 \cdot 28 \\
13 \cdot 80 \\
53 \cdot 33\end{array}$ & $\begin{array}{r}151 \\
113 \\
103 \\
73 \\
100 \\
119 \\
94 \\
111\end{array}$ & $\begin{array}{r}231 \\
98 \\
87 \\
54 \\
93 \\
119 \\
-110\end{array}$ & $\begin{array}{r}176 \\
107 \\
111 \\
65 \\
109 \\
117 \\
120\end{array}$ \\
\hline All causes & 1542 & $1337 \cdot 59$ & 441 & $350-07$ & 1983 & $1687 \cdot 66$ & $117 * * *$ & 98 & $117^{* * *}$ \\
\hline
\end{tabular}

*p < 0.05; **p < 0.01; ***p < 0.001. 
Table 4 Observed $(O)$ and expected $(E)$ deaths from selected causes by duration of employment and time since first employment

\begin{tabular}{|c|c|c|c|c|c|c|c|c|c|c|c|}
\hline \multirow[b]{3}{*}{ Cause of death } & \multicolumn{11}{|c|}{ Time since first employment (years) } \\
\hline & \multirow{2}{*}{$\begin{array}{l}\text { Duration of } \\
\text { employment } \\
\text { (years) }\end{array}$} & \multicolumn{2}{|c|}{$<10$} & \multicolumn{2}{|c|}{$10-19$} & \multicolumn{2}{|c|}{$20-29$} & \multicolumn{2}{|c|}{$\geqslant 30$} & \multicolumn{2}{|c|}{ Total } \\
\hline & & $O$ & $E$ & $O$ & $E$ & $O$ & $\boldsymbol{E}$ & $O$ & $E$ & $O$ & $E$ \\
\hline $\begin{array}{l}\text { Pharynx } \\
\text { Larynx } \\
\text { Other cancers of buccal cavity } \\
\text { and upper respiratory } \\
\text { tract* }\end{array}$ & $\begin{array}{l}<3 \\
\geqslant 3 \\
<3 \\
\geqslant 3 \\
y<3\end{array}$ & $\begin{array}{l}0 \\
1 \\
0 \\
0 \\
0\end{array}$ & $\begin{array}{l}0.09 \\
0.06 \\
0.23 \\
0.16 \\
0.24\end{array}$ & $\begin{array}{l}0 \\
3 \\
1 \\
2 \\
2\end{array}$ & $\begin{array}{l}0.31 \\
0.22 \\
0.48 \\
0.36 \\
0.51\end{array}$ & $\begin{array}{l}1 \\
6 \\
1 \\
1 \\
3\end{array}$ & $\begin{array}{l}0.37 \\
0.27 \\
0.61 \\
0.44 \\
0.58\end{array}$ & $\begin{array}{l}1 \\
1 \\
3 \\
2 \\
1\end{array}$ & $\begin{array}{l}0.47 \\
0.35 \\
0.78 \\
0.59 \\
0.75\end{array}$ & $\begin{array}{r}2 \\
11 \\
5 \\
5 \\
6\end{array}$ & $\begin{array}{l}1.24 \\
0.90 \\
2.10 \\
1.55 \\
2.08\end{array}$ \\
\hline $\begin{array}{l}\text { Oesophagus } \\
\text { Stomach } \\
\text { Lung } \\
\text { Respiratory disease }\end{array}$ & $\begin{array}{l}\geqslant 3 \\
<3 \\
\geqslant 3 \\
<3 \\
\geqslant 33 \\
<3 \\
\geqslant 3 \\
<3 \\
\geqslant 3\end{array}$ & $\begin{array}{r}0 \\
1 \\
1 \\
4 \\
3 \\
3 \\
6 \\
16 \\
10\end{array}$ & $\begin{array}{l}0.16 \\
0.37 \\
0.25 \\
2.55 \\
1.65 \\
3.78 \\
2.21 \\
8.92 \\
5.66\end{array}$ & $\begin{array}{r}1 \\
2 \\
1 \\
8 \\
7 \\
20 \\
26 \\
36 \\
17\end{array}$ & $\begin{array}{r}0 \cdot 39 \\
0 \cdot 85 \\
0 \cdot 61 \\
5 \cdot 69 \\
4 \cdot 13 \\
13 \cdot 46 \\
9 \cdot 16 \\
21 \cdot 75 \\
15.99\end{array}$ & $\begin{array}{r}0 \\
5 \\
0 \\
9 \\
6 \\
26 \\
23 \\
47 \\
28\end{array}$ & $\begin{array}{r}0 \cdot 43 \\
1 \cdot 38 \\
0 \cdot 97 \\
7 \cdot 14 \\
5 \cdot 20 \\
23 \cdot 32 \\
16 \cdot 25 \\
34 \cdot 15 \\
25 \cdot 31\end{array}$ & $\begin{array}{r}5 \\
4 \\
2 \\
9 \\
7 \\
49 \\
36 \\
72 \\
57\end{array}$ & $\begin{aligned} 0.56 \\
2.43 \\
1 \cdot 80 \\
8 \cdot 50 \\
6.59 \\
33.89 \\
25 \cdot 61 \\
48 \cdot 19 \\
38 \cdot 70\end{aligned}$ & $\begin{array}{r}6 \\
12 \\
4 \\
30 \\
23 \\
98 \\
91 \\
171 \\
112\end{array}$ & $\begin{array}{r}1.54 \\
5.02 \\
3.63 \\
23.88 \\
17.56 \\
74.45 \\
53.23 \\
113.02 \\
85.25\end{array}$ \\
\hline Man-years of observation & $\begin{array}{l}<3 \\
\geqslant 3\end{array}$ & & $\begin{array}{l}92.8 \\
164.7\end{array}$ & & $\begin{array}{l}448 \cdot 1 \\
526 \cdot 2\end{array}$ & & $\begin{array}{l}97 \cdot 4 \\
57 \cdot 3\end{array}$ & & $\begin{array}{l}860.8 \\
331.8\end{array}$ & & 899.1 \\
\hline
\end{tabular}

*Lip, tongue, salivary gland, mouth, and nose (9th rev ICD codes 140-145, 160).

significant excess mortality by comparison with national experience.

\section{CASE-CONTROL ANALYSIS}

The strongest evidence for an occupational hazard of cancer is provided by a positive relation between risk and level or duration of exposure. No measurements of the level of exposure were available, but we were able to analyse the relations between risk and total duration of employment, employment during different periods, type of employment, and time since first exposure. To determine which measure of exposure gave the best explanation of the results, we first conducted a matched case-control analysis based on those cancers which showed the largest excess. For this purpose, we included all deaths from or incident cases of cancers of the larynx, pharynx, lip, tongue, salivary gland, mouth, or nose, including cancers mentioned on the death certificate that were not the underlying cause. For each of these 48 cases (in 36 of which the cancer was said to have been the cause of death) up to 10 controls were chosen randomly from the subset of individuals in the cohort with the same sex and year of birth who were alive and free of cancer at the age when the case was diagnosed or died. Thus 452 controls were selected. The effects of the various factors were then estimated by a conditional logistic regression, using the computer program PECAN. ${ }^{13}$

Analysis restricted to the $\mathbf{4 0}$ cases and $\mathbf{4 0 4}$ controls whose job at entry was specified suggested that process workers suffered a substantially higher risk than other workers. There was little or no difference between the other four groups (tradesmen in process areas, workshop jobs, labourers, others) and in subsequent analyses workers were therefore classified as process or non-process. The present analysis also showed a consistent increase in risk with total duration of employment.

Workers specified as process workers on the discharge register showed a somewhat increased risk but the effect was less pronounced than that based on the job at entry.

\section{COHORT ANALYSIS: DURATION OF EMPLOYMENT}

AND TIME SINCE FIRST EMPLOYMENT

Further cohort analysis has been restricted to causes of death showing excess mortality by comparison with national or local rates-namely, cancers of the pharynx, larynx, other buccal cavity, and upper respiratory tract sites (comprising lip, tongue, salivary gland, mouth, and nose), lung, oesophagus, stomach, and non-malignant respiratory disease. These analyses have been restricted to men, since women contribute little to the total excess. Table 4 shows the observed and expected numbers of deaths by duration of employment and time since first employment. The SMR is higher in workers employed for three or more years than in those employed for less than three years by a factor of 7.6 for cancer of the pharynx and by factors of $1.4,1.3$, and 1.4 for cancers of the larynx, lung, and other upper respiratory tract sites, though the difference in SMR is significant only for cancers of 
Table 5 Observed $(O)$ and expected $(E)$ deaths from selected causes for workers specified as process workers $(P R)$, nonprocess workers (NP), or not specified (NS) at entry by duration of employment

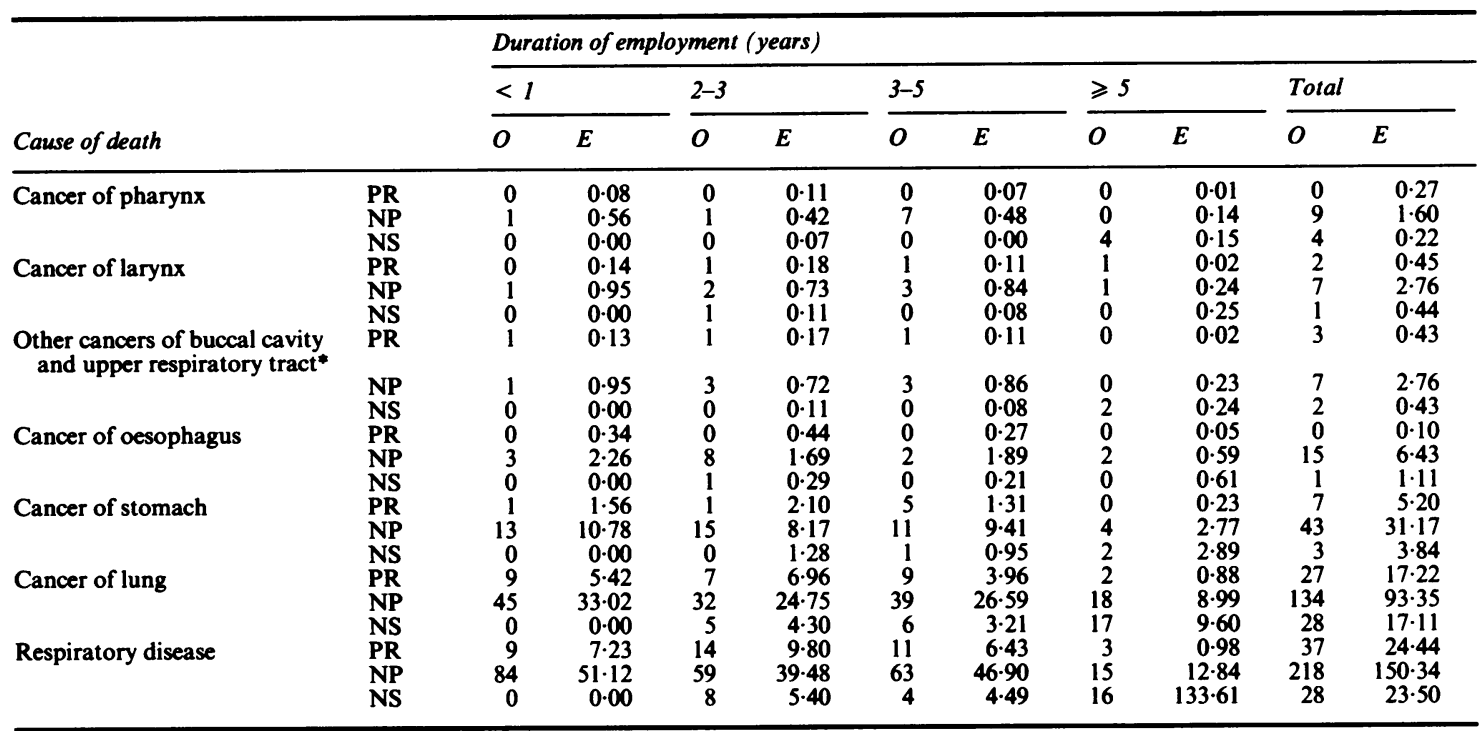

*Lip, tongue, salivary gland, mouth, and nose (9th rev ICD codes 140-145, 160).

the pharynx $(p=0.002)$ and lung $(p=0.04)$. There is little or no difference between short and long exposure in the SMR for stomach cancer, and for cancer of the oesophagus and respiratory disease the risk is somewhat lower in the group with longer employment. (Similar significance levels are also obtained when the trend in SMR is examined across four categories of duration of employment.)

The lung cancer SMR was highest in the period up to 20 years since first employment (SMR $=192$ less than 20 years after entry, and 135 beyond 20 years: $p=0.03$ two tailed), although the absolute excess risk was greater after a longer interval $\left(8.5 \times 10^{-4}\right.$ per man year up to 20 years since first employment and 12.2 $\times 10^{-4}$ per man-year more than 20 years since first employment).

The difference between process and other workers suggested by the case-control analysis is less pronounced in the cohort analysis. None of the individual causes shows a significantly higher risk in process workers (table 5), although their SMR for the cancers included in the case-control study (435) was slightly greater than that in non-process workers (323).

For stomach cancer, the excess is largely confined to the period up to 20 years since first employment, and there is no relation with duration of employment.

The overall SMR for non-malignant respiratory disease shows little or no relation with type or duration of employment (table 5) or with time since first exposure (table 4). In table 5 there is some suggestion of a consistent increase in risk for this cause with increasing duration of employment among men initially employed as process workers, but the trend is not statistically significant $(p=0 \cdot 23$ ).

There are too few deaths from the other cancers shown in tables 4 and 5 for detailed analysis, but none shows any obvious trend in risk with time since first employment.

\section{Discussion}

Our observations are (with one proviso) broadly consistent with those on Japanese mustard gas workers who were heavily exposed between 1929 and 1945, in whom Wada and his colleagues found five cancers of the larynx, 20 of the bronchus or lung, one of the trachea, three of the pharynx, one of the tongue, and three of the paranasal sinuses by comparison with an expected total of $0.9 .^{5}$ The SMRs were much lower in our cohort, particularly for cancer of the lung; but it should be noted that Japanese cigarette consumption was low until the 1950s and Japanese mortality from cancer of the lung was therefore also low until after the 1960s. There is no material difference between our data and the Japanese results in the distribution among these sites of the absolute excess of observed deaths over expected. Our results and those of Wada et al, are, therefore, broadly consistent on the assumption that the hazard of lung cancer produced by exposure to mustard gas adds to rather than multiplies the risk due to smoking. This would imply a substantial risk of lung cancer among non-smokers but in the 
absence of any data on smoking we cannot test this prediction. Apart from the excess of laryngeal cancer observed in the earlier study of workers at this factory, ${ }^{6}$ no increased risk of cancer has been clearly shown in either workers or servicemen exposed to mustard gas outside Japan, but neither the Japanese study nor the previous study of this factory was based on complete factory records. The excesses of cancers of the pharynx, larynx, and other upper respiratory tract sites observed in our cohort are too large to be accounted for by confounding factors, increased with duration of employment and were limited to the period more than 10 years after first employment, when the risk was increased fourfold. There can, therefore, be no doubt that cancers in these sites were caused by the exposure, though the number of deaths at individual sites, other than the pharynx and larynx, are too small to be sure that all were equally (or indeed at all) at risk.

In terms of absolute risk the excess of the lung cancer is more important, since lung cancers account for more than half the overall excess over expected for respiratory cancers. Much of this excess could be accounted for by the use of national or Cheshire urban district rates for comparison rather than the rates for Merseyside; but the Japanese results, together with the fact that the SMR was greatest in workers employed for three years or more, suggest that some of the excess was likely to have been real.

The choice of appropriate comparison mortality rates represents a serious difficulty in this study, particularly in interpreting the excesses of cancers of the lung, stomach, and oesophagus and of non-malignant respiratory disease. For each of these causes of death Merseyside has had exceptionally high rates during the period of this study, whereas Cheshire urban rates are more similar to the national rates. The works were on the south bank of the Mersey about 15 miles from Liverpool. When a random sample of 203 of the addresses of individuals on the discharge register were examined only $42(21 \%)$ fell within the Merseyside conurbation, with $74(38 \%)$ in Cheshire urban areas and $87(43 \%)$ in rural Cheshire, Lancashire, and elsewhere (where the rates for the above diseases, as in Cheshire urban districts, were not exceptionally high).

Thus if no migration had occurred the Merseyside rates should have had only a relatively small impact on the mortality of the cohort. It is thought, however, that a proportion of the workforce were attracted from Merseyside to work in the factory. The extent to which this could have influenced the underlying mortality is unknown, but it is reasonable to assume that the appropriate SMRs lie somewhere between those obtained from national and Merseyside rates. Such an adjustment could substantially alter the pattern of absolute excess risk of lung cancer in relation to time since first exposure, as expected numbers were calculated from national rates. We cannot, therefore, use our results to formulate reliable incidence models either for lung cancer or for buccal and upper respiratory cancers. The excess risk of lung cancer is only moderate and the comparison rates are uncertain, whereas for these other sites the total number of deaths is small.

The risk of respiratory cancer was not notably localised to individuals employed in process areas, which may indicate that the risk of cancer was due more to ambient levels of mustard gas in the factory than to the high levels to which process workers were exposed for short periods.

Quite substantial excesses were observed for two sites for which no previous evidence of a risk of cancer in mustard gas workers had been suspected-namely, oesophagus and stomach. Neither showed any positive relation with duration or type of work and for cancer of the oesophagus the excess was greater in men who were employed for less than three years than in men who had been employed for longer. These sites deserve consideration in any future studies, but our data do not provide convincing evidence that these cancers may be caused by mustard gas.

The excess mortality from non-malignant respiratory disease is difficult to interpret. The SMRs for both chronic bronchitis and acute respiratory disease would be substantially reduced, to 114 and 108 respectively, if the Merseyside population were the appropriate comparison group. In normal circumstances chronic bronchitis is almost exclusively confined to cigarette smokers, ${ }^{14}$ and an increased risk could be accounted for if smokers were overrepresented in this workforce. In addition there is the possibility that an initially unhealthy workforce was selected, perhaps due to wartime employment factors; this might have much more impact on nonmalignant respiratory disease than on cancer mortality. Against this, the excess of chronic bronchitis is consistent with the excess observed in British soldiers pensioned after mustard gas poisoning $^{3}$ and the excess of acute respiratory deaths with that observed in the United States first world war veterans. ${ }^{1}$ On balance, some of the excess mortality from respiratory disease was probably the result of exposure to mustard gas but the magnitude of the risk is uncertain.

We thank the parent company and the government department concerned for their cooperation in carrying out this study and the staff at the NHS Central Register for tracing the cohort. We also thank Derek Swift for help in identifying the cohort, Irene Stratton and Janis Davidson for computing help, and Sandra 
McVeigh for typing this manuscript. The Institute of Cancer Research receives support from the Cancer Research Campaign and the Medical Research Council.

\section{References}

1 Beebe GW. Lung cancer in world war I veterans: possible relation to mustard gas injury and 1918 influenza epidemic. JNCI 1960;25:1231-52.

2 International Agency for Research on Cancer. Monographs on the evaluation of carcinogenic risk of chemicals to man: some aziridines, $N$-, $S$ - and $O$ - mustards and selenium. Vol 9. Lyon: IARC 1975.

3 Case RAM, Lea AJ. Mustard gas poisoning, chronic bronchitis and lung cancer. An investigation into the possibility that poisoning by mustard gas in the 1914-18 war might be a factor in the production of neoplasia. BrJ Prev Soc Med 1955;9:62-72.

4 Norman JE. Lung cancer mortality in world war I veterans with mustard gas injury: 1919-1965. JNCI 1975;54:311-7.

5 Wada S, Nishimoto Y, Miyanishi M, Kambe S, Miller RW. Mustard gas as a cause of respiratory neoplasia in man. Lancet 1968;:1161-3.
6 Manning KP, Skegg DCG, Stell PM, Doll R. Cancer of the larynx and other occupational hazards of mustard gas workers. Clin Otolaryngol 1981;6:165-70.

7 American Cancer Society. Manual of tumor nomenclature and coding. New York: American Cancer Society, 1968.

8 World Health Organisation. International classification of diseases for oncology. Geneva: WHO, 1976.

9 Case RAM, Coghill C, Davies JM, et al. Serial mortality tables: neoplastic diseases. Vol 1. London: Institute of Cancer Research, 1976.

10 Office of Population Censuses and Surveys. Area mortality tables. Registrar General's decennial supplement for England and Wales 1969-73. (Series DS No 3.) London: Office of Population Censuses and Surveys, 1979.

11 Berry G. The analysis of mortality by the subject years method. Biometrics 1983;39:173-84.

12 Breslow NE. Elementary methods of cohort analysis. Int $J$ Epidemiol 1983;13:112-5.

13 Storer BE, Wacholder S, Breslow NE. Maximum likelihood fitting of general risk model to stratified data. Applied Statistics 1983;32:172-81.

14 Fletcher C, Peto R, Tinker C, Speizer FE. The natural history of chronic bronchitis and emphysema. Oxford: Oxford University Press, 1976.

\section{Correspondence and editorials}

The British Journal of Industrial Medicine welcomes correspondence relating to any of the material appearing in the journal. Results from preliminary or small scale studies may also be published in the correspondence column if this seems appropriate. Letters should be not more than 500 words in length and contain a minimum of references. Tables and figures should be kept to an absolute minimum. Letters are accepted on the understanding that they may be subject to editorial revision and shortening.

The journal now also publishes editorials which are normally specially commissioned. The Editor welcomes suggestions regarding suitable topics; those wishing to submit an editorial, however, should do so only after discussion with the Editor. 